\title{
RAZGLEDI
}

\section{DOSTOPNOST DO JAVNEGA POTNIŠKEGA PROMETA KOT POGOJ ZA SOCIALNO VKLJUČENOST DIJAKOV}

\author{
AVTORJA \\ dr. Matej Gabrovec \\ Znanstvenoraziskovalni center Slovenske akademije znanosti in umetnosti, Geografski inštitut Antona Melika, \\ Gosposka ulica 13, SI - 1000 Ljubljana, Slovenija \\ matej@zrc-sazu.si
}

\section{dr. Nika Razpotnik Visković}

Znanstvenoraziskovalni center Slovenske akademije znanosti in umetnosti, Geografski inštitut Antona Melika, Gosposka ulica 13, SI - 1000 Ljubljana, Slovenija

nika.razpotnik@zrc-sazu.si

DOI: $10.3986 / G V 90206$

UDK: 911.3:656.025.2(497.451)

COBISS: 1.01

\section{IZVLEČEK}

\section{Dostopnost do javnega potniškega prometa kot pogoj za socialno vključenost dijakov}

Na območju Ljubljanske urbane regije smo analizirali, kakšen delež dijakov ima ustrezen dostop do javnega potniškega prometa. Izračuni so bili narejeni na ravni posameznih stavb oziroma hišnih številk. Med posameznimi občinami so občutne razlike, na nekaterih hribovitih območjih obstaja tveganje socialne izključenosti mladostnikov zaradi prostorske nedostopnosti.

\section{KLJUČNE BESEDE}

geografija, javni potniški promet, dostopnost, trajnostna mobilnost, Ljubljanska urbana regija, Slovenija

\section{ABSTRACT}

\section{Accessibility to public transport as a condition for schoolchildren's social inclusion}

This study analyzes the share of secondary-school children with appropriate accessibility to public transport in the Ljubljana urban region. Calculations were made at the level of individual buildings. There are noticeable differences between the individual municipalities in the region, and in some hilly areas young people face the risk of social exclusion due to spatial inaccessibility.

\section{KEYWORDS}

geography, public transport, accessibility, sustainable mobility, Ljubljana urban region, Slovenia

Uredništvo je prispevek prejelo 26. junija 2018. 


\section{Uvod}

Socialna izključenost zaradi prostorske nedostopnosti storitev je najbolj pereča pri ranljivejših skupinah prebivalcev, predvsem pri mlajših in starejših. V Sloveniji je zaradi razpršene poselitve problematika nedostopnosti še toliko bolj pereča, saj na številnih podeželskih območjih ni mogoče organizirati učinkovitega javnega potniškega prometa ali pa je njegova organizacija povezana z nesorazmerno visokimi stroški. V Ljubljanski urbani regiji živi na takih območjih, kjer je gostota prebivalcev pod 200 na km², $14 \%$ prebivalcev (Gabrovec in Razpotnik Visković 2012), po posameznih občinah pa je ta delež še precej višji (glej preglednico 1). V članku obravnavamo dijake. Ti povečini zaradi svoje nepolnoletnosti ne morejo samostojno potovati kot vozniki osebnih vozil, zato so ne glede na svoj socialni položaj odvisni od javnega prometa ali pa jih morajo prevažati starši, drugi sorodniki ali znanci. Na nekaterih območjih zaradi slabe ponudbe javnega prevoza ne morejo dnevno potovati v šolo, zato morajo bivati v dijaških domovih in se lahko vračajo domov le ob vikendih. Marsikje javni promet sicer omogoča prevoz $\mathrm{v}$ šolo, vendar pa njegova ponudba ne omogoča udeležbe pri različnih popoldanskih obšolskih dejavnostih, kar spet lahko povzroči delno socialno izključenost. Prav pri teh dejavnostih so dijaki bolj odvisni od odraslih, ki jih vozijo z osebnim avtomobilom, kar je pokazala tudi raziskava v Avstriji in Nemčiji, narejena na podlagi potovalnih dnevnikov dijakov (Stark s sodelavci 2018).

Poleg vprašanja socialne izključenosti mladostnikov pa na tem mestu opozarjamo na še en, dolgoročni vidik urejanja dostopnosti do javnega potniškega prometa. Kot kažejo izsledki raziskav s področja vedenjske psihologije, na katere se opirajo tudi študije spodbujanja trajnostne mobilnosti, na posameznikovo izbiro prevoznega sredstva oziroma načina potovanja močno vplivajo njegove vsakodnevne navade. Ne glede na to, ali le-te razumemo kot avtomatizirana (Orbell in Verplanken 2010; Matthies, Klöckner in Preißner 2006) ali pa vsakokrat premišljena dejanja (Carlisle 2010), velja opozoriti, da je ravno obdobje odraščanja pomemben mejnik, ki določa naše navade v dobi odraslosti ter proces spreminjanja le-teh. V dobi odraslosti se namreč lažje vračamo k osebnim navadam, ki smo jih razvili že v mladosti, čeprav smo jih v vmesnem obdobju začasno opustili (Schwanen, Banister in Anable 2012). Kar zadeva vsakodnevni potniški promet, to pomeni, da se mora politika spodbujanja trajnostne mobilnosti osredotočiti tudi na mlade, saj je to ključnega pomena za oblikovanje njihovih kasnejših potovalnih navad. Pomembno je ozaveščanje (poudarjanje prednosti trajnostnih oblik potovanja na primer učinek na zdravje, stroškovni vidik, večja neodvisnosti), ki pa ga je treba vzporedno podpreti tudi s konkretnimi ukrepi, med njimi z zagotavljanjem dostopnega javnega prometa (Broberg in Sarjala 2015).

Prevoz osnovnošolskih otrok je $\mathrm{v}$ Sloveniji dobro urejen. V skladu $\mathrm{z}$ zakonom o osnovni šoli imajo učenci pravico do brezplačnega prevoza, če je njihovo prebivališče oddaljeno več kot štiri kilometre od osnovne šole, poleg tega imajo učenci 1. razreda pravico do brezplačnega prevoza ne glede na oddaljenost svojega prebivališča od osnovne šole, v ostalih razredih pa tudi, če pristojni organ za preventivo $\mathrm{v}$ cestnem prometu ugotovi, da je ogrožena varnost učenca na poti v šolo (Zakon o osnovni šoli 1996). Učenci srednjih šol imajo sicer pravico do subvencioniranih vozovnic na relaciji med bivališčem in šolo (Zakon o prevozih ... 2006), vendar pa pogosto v bližini njihovega doma ni postajališča javnega prometa oziroma s tega postajališča ni povezav ob ustreznem času.

Prostorski dostopnosti javnega potniškega prometa na državni ali regionalni ravni je bilo Sloveniji posvečenih že kar nekaj razprav (Gabrovec, Pavlin in Sluga 2000; Gabrovec in Bole 2006; Gabrovec in Razpotnik Visković 2012; Nared s sodelavci 2012). V navedenih primerih so bili prebivalstveni podatki zbrani na ravni posameznih hišnih številk, pri analizi javnega potniškega prometa pa je bila poleg lokacij postajališč upoštevana tudi frekvenca voženj. Podobno metodologijo uporablja tudi Evropska komisija (Poelman in Dijkstra 2015), vendar je le-ta namenjena preučevanju dostopnosti do javnega potniška prometa $\mathrm{v}$ mestih in primerjavi med evropskimi mesti. V tej razpravi smo metodologijo predhodnih študij ustrezno nadgradili, saj smo v njej upoštevali le dijake, ne pa vseh prebivalcev. Dostopnost do javnega potniškega prometa je prikazana po občinah. Na tej ravni sta vrednotila javni potniški pro- 
met Ogrin in Dovečar (2014), vendar pa sta se osredotočila predvsem na mestne občine, za vrednotenje pa sta uporabljala drugačne kazalce.

$\mathrm{V}$ analizi ne obravnavamo socialne izključenosti zaradi dohodkovne neenakosti, niti ne morebitne prostorske segregacije revnejših ali bogatejših slojev prebivalstva na različno dostopnih lokacijah, kar je predmet številnih razprav (na primer Glaeser, Kahn in Rappaport 2008). Dijaki lahko, ne glede na svoj socialni položaj, samostojno potujejo le v primeru, da je v primerni oddaljenosti od njihovega bivališča ustrezna ponudba javnega prevoza (v primeru bogatejših slojev prebivalstva je seveda tudi možna uporaba taksi prevozov, vendar ocenjujemo, da je delež dijakov, ki bi si lahko na podeželskih območjih redno privoščili uporabo te storitve zanemarljivo majhen). Menimo, da je pri načrtovanju omrežja javnega potniškega prometa treba upoštevati načelo socialne pravičnosti (Nazari Adli in Donovan 2018) in vsem prebivalcem omogočiti ustrezno dostopnost do javnega potniškega prometa, še posebej to velja za dijake in starejše. Seveda je pri tem treba upoštevati omejitve pri organizaciji javnega potniškega prometa, ki ga ni mogoče stroškovno učinkovito organizirati na redko poseljenih območjih.

Namen članka je s pomočjo analize ponudbe javnega potniškega prometa prikazati območja, v katerih dijaki nimajo možnosti dostopa do srednje šole z javnim prometom, ugotoviti ključne razloge slabe dostopnosti ter na podlagi analiz dobrih praks nakazati možnosti izboljšanja dostopnosti.

\section{Metode}

Vsi izračuni v analizah so pripravljeni na ravni posameznih stavb oziroma hišnih številk. Vir prebivalstvenih podatkov je Centralni register prebivalstva (2017). Kot dijake smo obravnavali vse prebivalce $\mathrm{v}$ starosti med 16 in 19 let oziroma z letnico rojstva med 1999 in 2002. Ocenjujemo, da je delež prebivalcev v tej starostni skupini, ki ne obiskuje srednje šole, zanemarljiv. Pri izračunavanju prikaza gostote poselitve smo uporabili metodologijo, ki smo jo razvili leta 2012 (Gabrovec in Razpotnik Visković 2012). Gostota je izračunana na ravni vsake stavbe s hišno številko tako, da ji je pripisano število prebivalcev $\mathrm{v}$ krogu, ki ima središče v tej stavbi in površino $1 \mathrm{~km}^{2}$.

Analizo oddaljenosti bivališč dijakov od postajališč javnega potniškega prometa smo naredili na dva načina. Pri prvem smo upoštevali vsa aktivna postajališča v Ljubljanski urbani regiji, pri drugem pa smo upoštevali le tista, na katerih je ponudba javnega prometa zadovoljiva, to pomeni, da vozni red omogoča pravočasen jutranji prihod v ljubljanske srednje šole in ustrezen popoldanski odhod. Kot kriterij smo postavili vsaj en prihod v Ljubljano pred 7. uro zjutraj in vsaj en odhod ob 15.30 ali kasneje ter vsaj pet parov voženj dnevno. Postavljen kriterij predstavlja res minimalno število, ki še omogoča socialno vključenost dijakov, nikakor pa ne predstavlja dobre povezave, ki bi spodbujala uporabo javnega potniškega prometa. Zavedamo se, da je za socialno vključenost zelo pomembna tudi možnost udeležbe na popoldanskih in večernih interesnih dejavnostih, zato bi bilo smiselno k minimalnemu kriteriju dodati še popoldanske in večerne vožnje. Vendar pa smo želeli izpostaviti, da v nekaterih občinah velik delež dijakov nima ustrezne povezave z javnim prometom niti za obiskovanje rednega pouka. Če bi kriterij zaostrili z zahtevo po popoldanskih in večernih vožnjah, se delež dijakov z zadovoljivo dostopnostjo ne bi bistveno zmanjšal, kajti na večini postajališč, ki ustrezajo postavljenim kriterijem, obstajajo tudi večerne povezave. Izpolnjevanje navedenih kriterijev smo preverili v voznih redih, ki so veljali 1. 1.2018, in sicer v medkrajevnih (AVRIS 2018) in mestnih (Ljubljanski ... 2018; Občina Logatec 2018) avtobusnih ter železniških (Slovenske železnice 2018). Podatke o lokacijah postajališč (stanje maja leta 2017) smo pridobili na Ministrstvu za infrastrukturo. Koordinate manjkajočih postajališč zaradi na novo uvedenih prog po maju leta 2017 v občinah Ljubljana, Medvode in Litija smo določili s pomočjo ortofoto posnetkov. 


\section{Rezultati}

Izračun gostote prebivalcev kaže na precejšnje razlike med občinami v Ljubljanski urbani regiji. Med kazalci izpostavljamo delež dijakov, ki živijo na območjih z gostoto, večjo od 250 prebivalcev na $\mathrm{km}^{2}$. Območja takšne gostote omogočajo organizacijo kakovostnega javnega potniškega prometa (Heußner s sodelavci 2001; Gabrovec in Razpotnik Visković 2012). Razpon tega deleža je med občinami Ljubljanske urbane regije zelo velik. V občinah Ljubljana, Trzin, Komenda in Log-Dragomer je ta delež večji od $95 \%$, kar pomeni, da je v teh občinah glede na poselitev večini prebivalcem možno omogočiti dostop do kakovostnega javnega potniškega prometa. Na drugi strani lestvice je občina Šmartno pri Litiji, kjer zgolj 23 \% dijakov živi na območjih z gostoto več kot 250 prebivalcev na km², v občinah Ivančna Gorica, Lukovica, Moravče in Velike Lašče pa je ta delež manjši od 40 \% (preglednica 1).

Zanimiva je primerjava gostote poselitve s ponudbo javnega potniška prometa. Ob predpostavki, da upravljavec javnega potniška prometa $\mathrm{v}$ vseh občinah uporablja enake standarde dostopnosti oziroma, da imajo enako velika naselja povsod približno enako ponudbo javnega potniškega prometa, bi občine $\mathrm{z}$ manjšo gostoto prebivalcev imele manjši delež prebivalcev z ustrezno dostopnostjo do postajališč javnega potniškega promet in obratno. Občine smo razvrstili po deležu dijakov na redko poseljenih območjih (pod 250 prebivalcev na $\mathrm{km}^{2}$ ) in deležu dijakov, ki živijo več kot $1 \mathrm{~km}$ od postajališča (slika 1), ter jih primerjali po rangu. V zgornjem in spodnjem delu lestvice ni bistvenih razlik. Vendarle pa lahko izdvojimo nekatere občine, kjer je ponudba javnega potniškega prometa nad- ali podpovprečna. Med prve se uvrščajo Škofljica, Vodice, Grosuplje in Ig, med druge pa Medvode, Komenda in Borovnica. Te razlike lahko razložimo $\mathrm{z}$ različno aktivnim urejanjem javnega potniškega prometa po posameznih občinah, kar bomo opisali v naslednjem poglavju.

Razdaljo do enega kilometra navadno ocenjujemo kot največjo, ki so jo ljudje še pripravljeni dnevno prepešačiti do postajališča javnega prometa (na primer Gabrovec, Pavlin in Sluga 2000). Iz slike 2 pa je razvidno, da v številnih občinah Ljubljanske urbane regije velik delež dijakov živi v hišah, ki so od najbližjega postajališča oddaljene več kot $2 \mathrm{~km}$. To pa je že razdalja, ki še posebej ob neugodnih vremenskih razmerah pomeni resno oviro za vsakodnevne poti in je posledično lahko vzrok za socialno izključenost.

Podrobneje nam oddaljenost bivališč dijakov od najbližjega postajališča prikazuje slika 3, kjer so z znaki različnih barv prikazana bivališča vseh dijakov. V Ljubljanski urbani regiji je kar nekaj večjih sklenjenih območij brez ustrezne povezave $\mathrm{z}$ javnim potniškim prometom, gre predvsem za hribovita območja. V Posavskem hribovju so le-ta na meji med občinama Kamnik in Lukovica ter Šmartnim pri Litiji in Ivančno Gorico ter na vzhodnem območju občine Litija. Na jugu izstopata Velikolaščanska pokrajina in Struge v občini Dobrepolje. Ponudba javnega potniškega prometa v slednji sicer omogoča dijakom pravočasen prihod $\mathrm{v}$ šolo, vendar pa so bila zaradi slabe frekvence (4 pari dnevno) postajališča v Strugah izločena iz nabora ustreznih. V severozahodnem delu Ljubljanske urbane regije so dijaki brez povezav z javnim prometom v delu Polhograjskega in Rovtarskega hribovja v občinah Medvode, Dobrova-Polhov Gradec in Logatec.

\section{Razprava}

Dijake z območij, ki nimajo ustrezne povezave z javnim prometom, do najbližjega postajališča ali tudi do kraja šolanja praviloma vozijo starši ali drugi sorodniki in znanci, ter s temi prevozi preprečujejo socialno izključenost. Vendarle pa menimo, da bi morala biti ponudba javnega prometa takšna, da bi vsem prebivalcem omogočala dostop do šolanja, dela in drugih dejavnosti, ne da bi bili odvisni od svojih sorodnikov in prijateljev. Dostop do postajališč je zlasti z vidika načel trajnostne mobilnosti smiselno spodbujati tudi s kolesi. V primeru slabo dostopnih območij v Ljubljanski urbani regiji gre praviloma za hribovita območja, kjer bi bila rešitev lahko uporaba električnih koles. Vendar pa bi bilo v tem primeru potrebno urediti ustrezno varovane kolesarnice, poleg tega pa je takšen prevoz problematičen v zimskih razmerah. 


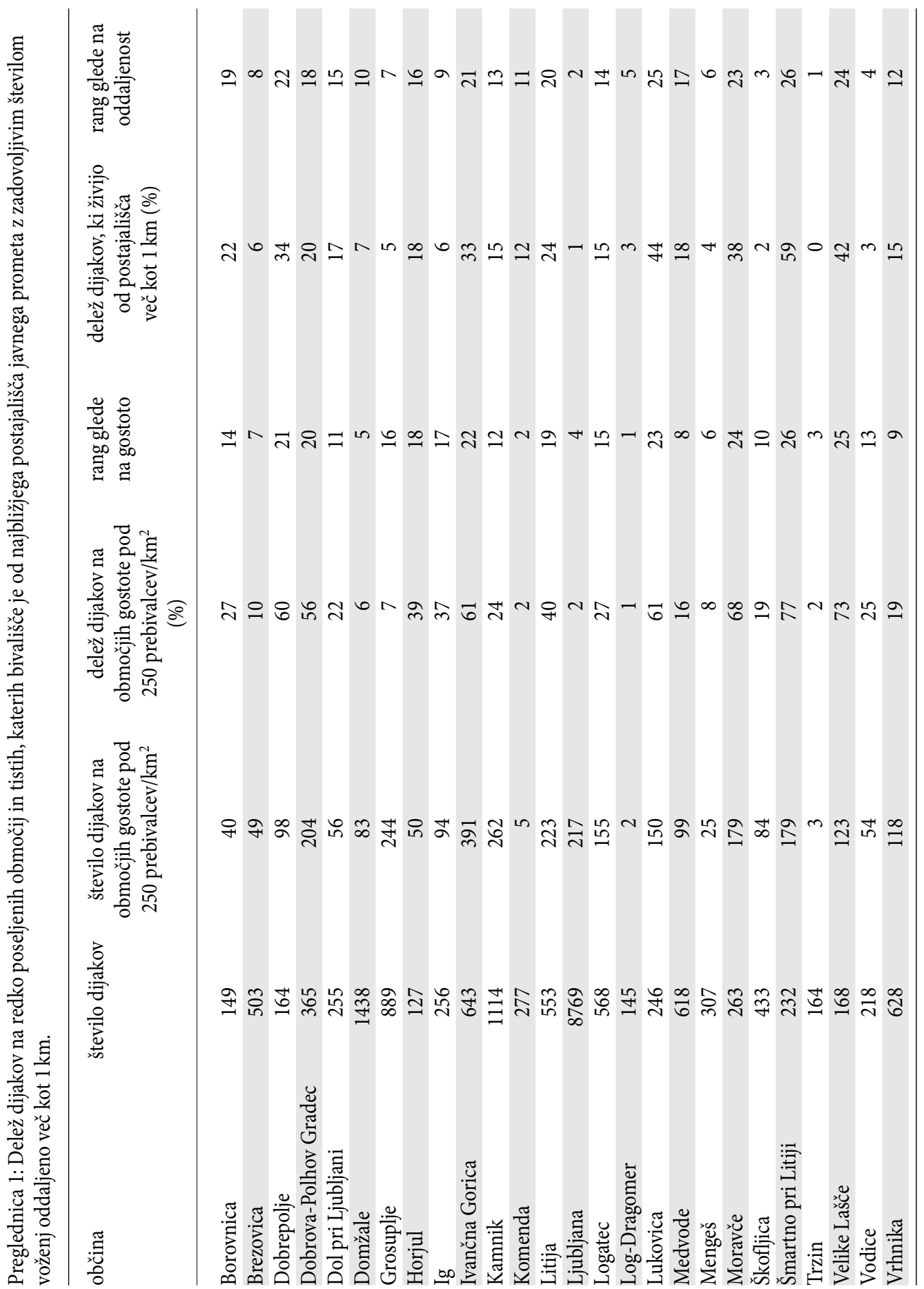




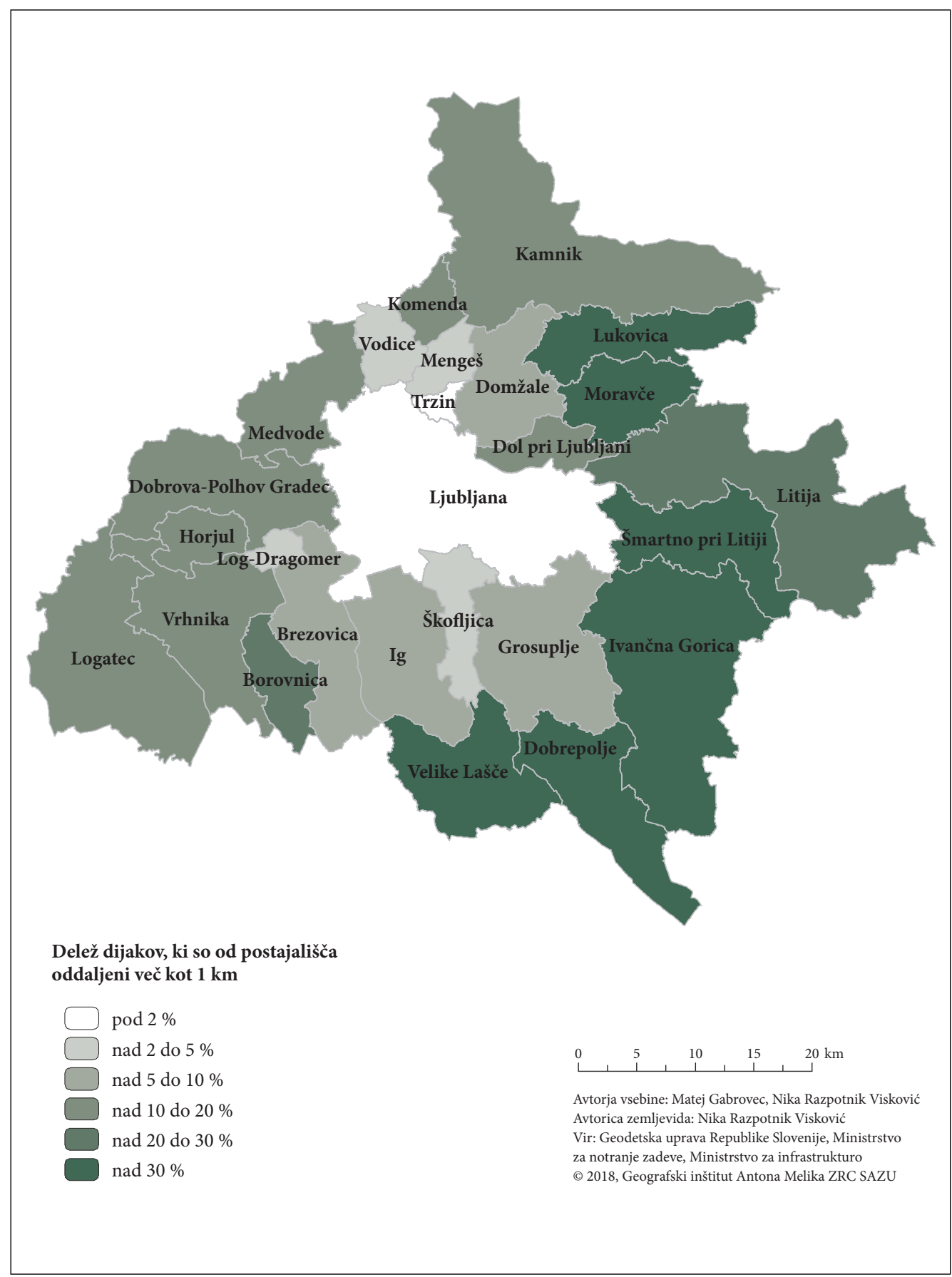

Slika 1: Delež dijakov v Ljubljanski urbani regiji, katerih bivališče je od najbližjega postajališča javnega prometa z zadovoljivim številom voženj oddaljeno več kot $1 \mathrm{~km}$. 


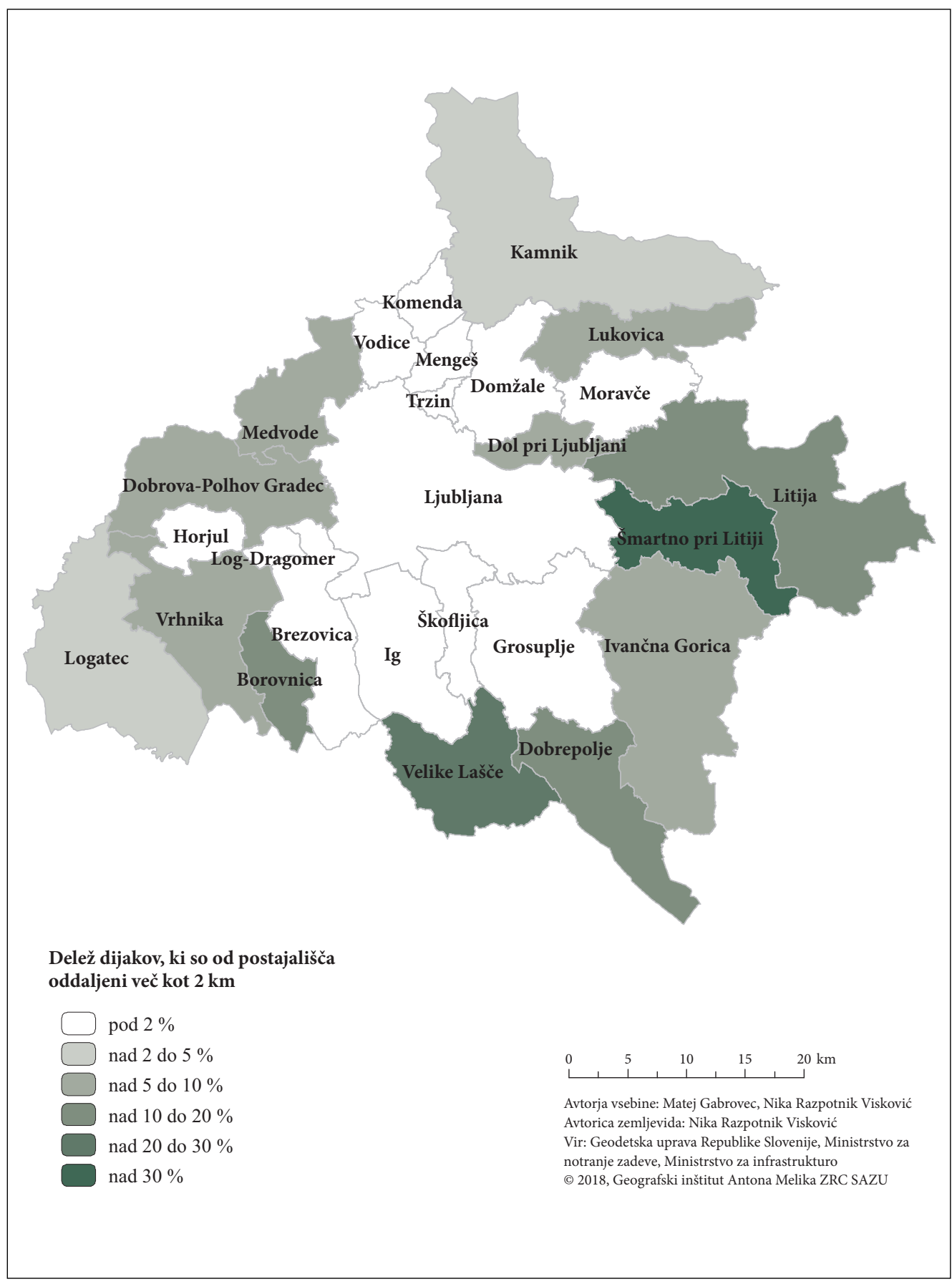

Slika 2: Delež dijakov v Ljubljanski urbani regiji, katerih bivališče je od najbližjega postajališča javnega prometa zadovoljivim številom voženj oddaljeno več kot $2 \mathrm{~km}$. 


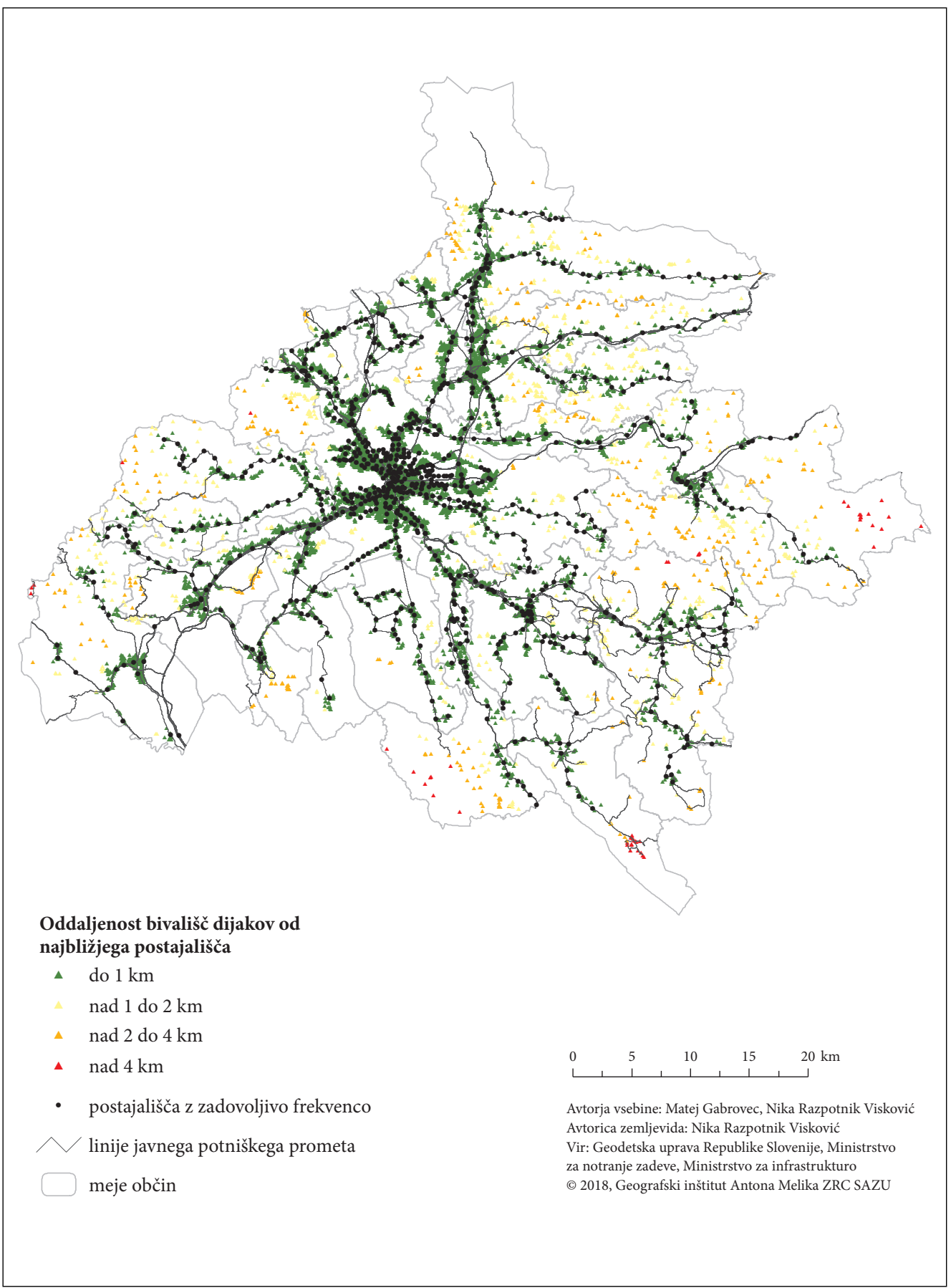

Slika 3: Stalna bivališča dijakov $v$ Ljubljanski urbani regiji in njihova oddaljenost do postajališč javnega prometa $z$ zadovoljivim številom voženj. 


\subsection{Primeri dobrih in slabših praks v regiji}

Avtobusni medkrajevni javni potniški promet je v skladu s slovensko zakonodajo v državni pristojnosti (Zakon o prevozih ... 2006), v občinski pristojnosti je le mestni promet. Ne glede na ta določila pa so v Ljubljanski urbani regiji pobude za izboljšave prihajale tudi z regijske in občinske ravni. Na regijski ravni so bile pripravljene strokovne podlage urejanje javnega prometa (Pelko 2010). Leta 2011 se je občina Grosuplje dogovorila z Mestno občino Ljubljano in Ljubljanskim potniškim prometom kot prevoznikom o združevanju mestnih in medkrajevnih linij oziroma uvedbi tako imenovane integrirane linije. Uvedena je bila tudi tarifna integracija, vzpostavljen je bil enotni tarifni conski sistem (Prinčič 2016). Vanj so bile vključene tudi lokalne linije znotraj občine Grosuplje. V šolskem letu 2012/2013 je občina Grosuplje začela tudi z združevanjem rednega in šolskega prevoza v Grosupljem na sedmih linijah. Šolski prevozi so bili v dogovoru med občino in Ministrstvom za infrastrukturo registrirani kot redne linije, hkrati pa so bile uvedene še dodatne vožnje, ki so bile prilagojene tudi potrebam dijakov, študentov in drugih uporabnikov (Otrin 2016). Zgledu Grosupljega so v naslednjih letih sledile tudi občine Škofljica, Ig, Vodice in Dobrova-Polhov Gradec. Te občine imajo zato boljšo dostopnost do javnega potniškega prometa kot bi jo pričakovali na podlagi gostote prebivalcev. Mestne linije so bile iz Ljubljane podaljšane tudi v občini Brezovica in Medvode; s tem ukrepom so se bistveno izboljšale povezave večjih naselij v teh občinah $\mathrm{z}$ Ljubljano. Ker pa $v$ teh občinah šolski prevoz ni integriran $v$ javni potniški promet; na primer v Medvodah prebivalci zahodnega, hribovitega dela občine nimajo povezave z javnim prometom. V nekaterih občinah, kot sta na primer Ivančna Gorica in Vrhnika, so šolske prevoze sicer registrirali kot redne linije, vendar pa v nasprotju z zgoraj omenjenimi občinami niso uvedli dodatnih voženj. Zaradi prepoznih oziroma prezgodnjih odhodov te linije niso uporabne za dijake za pot v šolo, vendarle pa vsaj starejšim prebivalcem, ki nimajo možnosti uporabe osebnega avtomobila, omogočajo osnovno mobilnost. Zanimiv je primer občine Borovnica, ki ima sicer časovno konkurenčno železniško povezavo z Ljubljano, od katere pa je nekaj vasi v južnem delu občine oddaljenih več kot $2 \mathrm{~km}$ in brez povezave $\mathrm{z}$ javnim prometom.

Vsi navedeni primeri kažejo, da je za preprečitev socialne izključenosti dijakov, zaradi prostorske nedostopnosti na območjih z nizko gostoto prebivalcev, najučinkovitejši ukrep združevanje rednih in šolskih linij. S takšnim združevanjem lahko dosežemo boljšo izkoriščenost vozil javnega potniškega prometa in s tem nižjo ceno na kilometer. Takšno združevanje sicer zahteva večje organizacijske napore, kajti šolski prevozi so v pristojnosti občin, redne medkrajevne linije pa v pristojnosti države. Potreben je torej ustrezen sporazum med lokalno skupnostjo, ministrstvom, pristojnim za promet in prevoznikom. Žal marsikatere lokalne skupnosti v Sloveniji problematiko šolskih prevozov rešujejo parcialno. Ker stroški šolskih prevozov predstavljajo velik strošek v občinskem proračunu, skušajo stroške le-teh čim bolj optimizirati z boljšo organizacijo teh prevozov (Dragan, Kramberger in Lipičnik 2011). Vendar pa je skupno razmerje med stroški in koristmi večje $z$ integracijo šolskih prevozov v javni potniški promet, kajti v tem primeru $\mathrm{z}$ le nekaj višjimi stroški izboljšamo dostopnost tudi drugim skupinam prebivalcev. Izziv za prihodnost še vedno ostaja povezava šolskih prevozov z alternativnimi oblikami javnega prevoza, kot so razne oblike prevozov na klic. S takšnimi bolj fleksibilnimi oblikami lahko v prihodnosti dosežemo še boljšo povezanost podeželskih območij z nižjimi stroški.

\section{Sklep}

Analiza dostopnosti do postajališč javnega potniškega prometa v Ljubljanski urbani regiji je pokazala precejšnje razlike med občinami, ki so v veliki meri posledica poselitvene sestave. Na območju Ljubljanske urbane regije kot celote živi $90 \%$ vseh dijakov v oddaljenosti manj od $1 \mathrm{~km}$ od najbližjega postajališča $\mathrm{z}$ ustrezno frekvenco voženj, kar $97 \%$ pa v razdalji manj kot $2 \mathrm{~km}$. Ta skupen podatek pa zakriva neprimerno dostopnost $\mathrm{v}$ posameznih občinah, kot na primer $\mathrm{v}$ občini Velike Lašče, kjer je 
dostopnost najslabša, saj kar 30 \% dijakov živi v oddaljenosti več kot $2 \mathrm{~km}$ od najbližjega postajališča. Primeri dobrih praks v regiji kažejo, da se dostopnost najučinkoviteje izboljša s skupnim načrtovanjem in združevanjem šolskih prevozov z rednimi avtobusnimi linijami.

Zahvala: Delo je bilo financirano v okviru projekta SMART-MR (program Interreg Europe), ki ga financira Evropski sklad za regionalni razvoj, ter v okviru raziskovalnega programa Geografija Slovenije (P6-0101), ki ga financira Javna agencija za raziskovalno dejavnost Republike Slovenije.

\section{Viri in literatura}

AVRIS (Avtobusni voznoredni informacijski sistem). Register gospodarske javne službe, januar 2018. Ministrstvo za infrastrukturo. Ljubljana, 2018. Medmrežje: ftp.drsc.si (10.2.2018).

Broberg, A., Sarjala, S. 2015: School travel mode choice and the characteristics of the urban built environment: The case of Helsinki, Finland. Transport Policy 37. DOI: https://doi.org/10.1016/ j.tranpol.2014.10.011

Carlisle, C. 2010: Between freedom and necessity: Félix Ravaisson on habit and the moral life. Inquiry 53-2. DOI: https://doi.org/10.1080/00201741003612146

Centralni register prebivalstva, stanje decembra 2017. Ministrstvo za notranje zadeve. Ljubljana, 2017.

Dragan, D., Kramberger, T., Lipičnik, M. 2011: Monte carlo simulation-based approach to optimal bus stops allocation in the Municipality of Laško. Promet - Traffic\&Transportation 23-4.

Gabrovec, M., Bole, D. 2006: Dostopnost do avtobusnih postajališč. Geografski vestnik 78-2.

Gabrovec, M., Pavlin, B., Sluga, G. 2000: Dostopnost do javnega potniškega prometa v Ljubljanki urbani regiji. Ljubljana: Geografija mesta. Ljubljana.

Gabrovec, M., Razpotnik Visković, N. 2012: Ustreznost omrežja javnega potniškega prometa v Ljubljanski urbani regiji z vidika razpršenosti poselitve. Geografski vestnik 84-2.

Glaeser, E. L., Kahn, M. E., Rappaport, J. 2008: Why do the poor live in cities? The role of public transportation. Journal of Urban Economics 63-1. DOI: https://doi.org/10.1016/j.jue.2006.12.004

Heußner, J., Kirchhoff, H.-H., Lapp, U., Meier, W., Meyer, L., Nickel, B. E., Roß, J., von Rumohr, V., Strünkmann, W. 2001: Verkehrserschließung und Verkehrsangebot im ÖPNV. VDV Schriften 4. Köln.

Ljubljanski potniški promet, Vozni redi. Mestni potniški promet. Ljubjana, 2018. Medmrežje: http://www.lpp.si/ javni-prevoz/vozni-redi (11.2.2018).

Matthies, E. A., Klöckner, C. A., Preißner, C. L. 2006: Applying a modified moral decision making model to change habitual car use: how can commitment be effective? Applied Psychology 55-1. DOI: https://doi.org/10.1111/j.1464-0597.2006.00237.x

Nared, J., Bole, D., Gabrovec, M., Geršič, M., Goluža, M., Razpotnik Visković, N., Rus, P. 2012: Celostno načrtovanje javnega potniškega prometa v Ljubljanski urbani regiji. Georitem 20. Ljubljana.

Nazari Adli, S., Donovan, S. 2018: Right to the city: Applying justice tests to public transport investments. Transport Policy 66. DOI: https://doi.org/10.1016/j.tranpol.2018.03.005

Občina Logatec, Logaški lokalni prevoz. Logatec, 2017. Medmrežje: https:/www.gslogatec.si/documents/ gslogatec/obrazci/Vozni-red-avtobusov-v-logaski-obcini_od-1-9-2017-dalje.pdf (12.2.2018).

Ogrin, M., Dovečar, M. 2014: Vrednotenje sistemov javnega potniškega prometa v izbranih občinah Slovenije. Dela 42. DOI: https://doi.org/10.4312/dela.42.6.115-127

Orbell, S., Verplanken, B. 2010: The automatic component of habit in health behavior: habit as cuecontingent automaticity. Health Psychology 29-4. DOI: https://doi.org/10.1037/a0019596

Otrin, K. 2016: Združevanje linij rednega in šolskega avtobusnega prevoza v Grosupljem. Trajnostna mobilnost v praksi: zbornik dobrih praks. Ljubljana.

Pelko, N. (ur.) 2010: Javni promet v Ljubljanski urbani regiji. Ljubljana. 
Poelman, H., Dijkstra, L. 2015: Measuring Access to Public Transport in European Cities. European Commission Working Papers 01/2015. Medmrežje: http://ec.europa.eu/regional_policy/sources/ docgener/work/2015_01_publ_transp.pdf (11.2.2018).

Prinčič, P. 2016: Podaljšanje avtobusnih linij v primestna naselja. Trajnostna mobilnost v praksi: zbornik dobrih praks. Ljubljana.

Schwanen, T., Banister, D., Anable, J. 2012: Rethinking habits and their role in behaviour change: the case of low-carbon mobility. Journal of Transport Geography 24. DOI: https://doi.org/10.1016/j.jtrangeo.2012.06.003

Slovenske železnice, Potniški promet: Vozni redi po relacijah. Ljubljana, 2017. Medmrežje: http://www.slozeleznice.si/sl/potniki/vozni-redi/osnutki-voznih-redov-po-relacijah-2016-2017 (11.2.2018).

Stark, J., Beyer Bartana, I., Fritz, A., Unbehaun, W., Hössinger, R. 2018: The influence of external factors on children's travel mode: A comparison of school trips and non-school trips. Journal of Transport Geography 68. DOI: https://doi.org/10.1016/j.jtrangeo.2018.02.012

Zakon o osnovni šoli. Uradni list Republike Slovenije 12/1996. Ljubljana.

Zakon o prevozih v cestnem prometu. Uradni list Republike Slovenije 131/2006. Ljubljana.

\section{Summary: Accessibility to public transport as a condition for schoolchildren's social inclusion}

(translated by DEKS d. o. o.)

Social exclusion due to spatial inaccessibility of services is most pressing for vulnerable population groups, and especially among young people and the elderly. Due to dispersed settlement, in Slovenia the problem of inaccessibility is all the more pressing because in many rural areas it is not possible to set up effective public transport, or doing so would be disproportionately expensive. This article examines the situation for secondary-school children. Because they are minors, they are generally not permitted to drive alone, and so regardless of their social position they depend on public transport or must be driven by their parents, other relatives, or acquaintances. In some areas, the poor availability of public transport means that they cannot commute to school, and so they must stay in school dormitories and can travel home only on the weekends. In many places, they can use public transport to get to school, but it is insufficient to allow them to participate in various afternoon extracurricular activities, which can also cause some degree of social isolation. In addition to the issue of young people's social exclusion, this article also draws attention to the long-term aspect of making public transport accessible. As indicated by the findings of studies in behavioral psychology, which are also used by studies of sustainable mobility promotion, an individual's choice of transport mode of travel can also be greatly influenced by everyday habits. Regardless of whether these are understood as automatized (Orbell and Verplanken 2010; Matthies, Klöckner and Preißner 2006) or as deliberate actions each time (Carlisle 2010), it should be pointed out that the period of growing up is an important milestone that defines one's habits in adulthood and the process of changing them. During adulthood, one can more easily return to personal habits that were already developed in childhood, even if they were temporarily abandoned in the intervening period (Schwanen, Banister and Anable 2012). Regarding everyday public transport, this means that the policy of promoting sustainable mobility must also focus on young people because this is of key importance for shaping their later transportation habits. It is important to raise their awareness, and this must be supported in parallel with concrete measures, including providing access to public transport (Broberg and Sarjala 2015).

This analysis does not deal with social exclusion as a result of income inequality, nor possible spatial segregation of poorer and wealthier population strata in locations of varying accessibility, which has been addressed by various studies (e.g., Glaeser, Kahn and Rappaport 2008). Regardless of their social position, secondary-school children can travel independently only if there is suitable public transport 
available in appropriate proximity to their residences. In planning a public transport network, it is necessary to take into account the principle of social justice (Nazari Adli and Donovan 2018) and to provide suitable access to public transport for all residents, and especially for secondary-school children and the elderly.

All of the calculations in the analyses were prepared at the level of individual buildings. The source for residence data was the Central Population Register (December 2017). In calculating population density, a method was used that the authors developed in 2012 (Gabrovec and Razpotnik Visković 2012). Density is calculated for each building with a house number such that the number of residents in a circle centered on that building with an area of $1 \mathrm{~km}^{2}$ is ascribed to it.

The calculation of population density indicates considerable differences among the municipalities in the Ljubljana urban region. Among the indicators, the share of secondary-school children that live in areas with a density greater than 250 inhabitants per $\mathrm{km}^{2}$ stands out. Areas with such a density make it possible to set up quality public transport (Heußner et al. 2001; Gabrovec and Razpotnik Visković 2012).

It is interesting to compare population density with public transport availability. Assuming that public transport providers used the same accessibility standards in all municipalities or that settlements of equal size will have roughly the same public transport availability, municipalities with a lower population density should have a smaller share of residents with suitable access to public transport stops and vice versa. However, some municipalities can be singled out where the available public transport is above or below average. These differences are the result of different transport policies.

A distance of up to one kilometer is usually assessed as the farthest that people are willing to walk to a public transport stop on a daily basis (e.g., Gabrovec, Pavlin and Sluga 2000). Figure 2 shows that in many municipalities in the Ljubljana urban region a large share of secondary-school children live in houses where the nearest public transport stop is over two kilometers away. Especially in poor weather, such a distance represents a serious obstacle to a daily route and consequently may cause social exclusion.

In line with Slovenian legislation, regional and local public bus transport falls under national authority (Road Transport Act; Zakon o prevozih ... 2006), and municipal authority covers only traffic in towns. Regardless of these provisions, in the Ljubljana urban region initiatives for improvement have also come from the regional and municipal levels. At the regional level, expert bases have been prepared for managing public transport (Pelko 2010). In 2011, the Municipality of Grosuplje made an agreement with the City of Ljubljana and the Ljubljana Public Transport (LPP) company as a transport operator on merging city and regional bus routes, and introducing "integrated « routes. Fare integration was introduced and an integrated fare zone system was established (Prinčič 2016). It also included local routes within the Municipality of Grosuplje. During the 2012/2013 school year, the Municipality of Grosuplje also started combining regular and school transport in Grosuplje on seven routes. School transport was registered as regular routes in an agreement between the municipality and the Ministry of Infrastructure, and at the same time additional routes were introduced that were also adapted to the needs of secondary-school children, university students, and other users (Otrin 2016). Grosuplje's model was also followed by certain other municipalities in subsequent years. This example shows that combining regular and school routes is the most effective measure for preventing social exclusion of secondaryschool children due to spatial inaccessibility in areas with low population density. Such a merger can result in better use of public transport vehicles and thus lower costs per kilometer. It requires greater organizational efforts because school transport is the responsibility of the municipalities and scheduled bus routes are a national responsibility. It is therefore necessary to have a suitable agreement between the local community and the ministry responsible for transport. The challenge for the future remains connecting school transport with alternative forms of public transport, such as various forms of calland-ride services. With more flexible forms like this, it is possible to achieve even better connections for rural areas at lower costs in the future. 